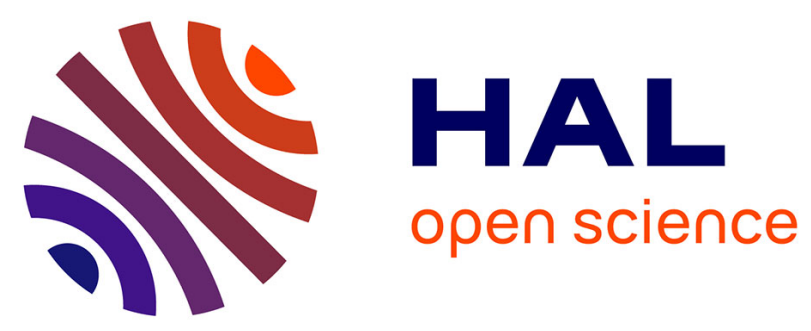

\title{
Anomalous fluid properties of carbon dioxide in the supercritical region - Application to geological CO 2 storage and related hazards
}

\author{
A. Imre, Claire Ramboz, T Kraska, U.K. Deiters
}

\section{To cite this version:}

A. Imre, Claire Ramboz, T Kraska, U.K. Deiters. Anomalous fluid properties of carbon dioxide in the supercritical region - Application to geological CO 2 storage and related hazards. Environmental Earth Sciences, 2015, 73, pp.4373-4384. 10.1007/s12665-014-3716-5 . insu-01090267

\section{HAL Id: insu-01090267} https://hal-insu.archives-ouvertes.fr/insu-01090267

Submitted on 3 Dec 2014

HAL is a multi-disciplinary open access archive for the deposit and dissemination of scientific research documents, whether they are published or not. The documents may come from teaching and research institutions in France or abroad, or from public or private research centers.
L'archive ouverte pluridisciplinaire HAL, est destinée au dépôt et à la diffusion de documents scientifiques de niveau recherche, publiés ou non, émanant des établissements d'enseignement et de recherche français ou étrangers, des laboratoires publics ou privés. 
Anomalous fluid properties of carbon dioxide in the supercritical region - Application to geological $\mathrm{CO}_{2}$ storage and related hazards.

A. R. Imre. $\left(1,2,3,{ }^{*}\right)$, C. Ramboz (2,4,5), U.K. Deiters (3) and T. Kraska (3)

(1) MTA Centre for Energy Research, Thermohydraulics Department, P.O. Box 49, H-1525 Budapest, Hungary

(2) Université d'Orleans, ISTO, UMR 7327, F-45071, Orléans, France

(3) University Cologne, Institute of Physical Chemistry, Luxemburger Str. 116, D-50939 Köln, Germany

(4) CNRS, ISTO, UMR 7327, F-45071 Orléans, France

(5) BRGM, ISTO, UMR 7327, BP 36009, F-45060 Orléans, France

* corresponding author, imre.attila@energia.mta.hu

\begin{abstract}
For supercritical fluids there is a wedge-shaped region called Widom region, where several physico-chemical quantities (e.g., compressibility, heat capacities, density, thermal expansivity, speed of sound) show anomalous behaviour. In this paper several Widom lines of supercritical $\mathrm{CO}_{2}$ have been computed with the Wagner-Span reference equation of state. The locations of the Widom lines are compared with the $P-T$ range of the Snøhvit, Sleipner, Nagaoka and Ketzin reservoirs, which are recently studied for their fitness for $\mathrm{CO}_{2}$ sequestration, and two natural $\mathrm{CO}_{2}$ storage analogues, Montmiral in France and MihályiRépcelak in Hungary. The potential consequences of leaking $\mathrm{CO}_{2}$ crossing any of the Widom lines are discussed.
\end{abstract}

Keywords: carbon sequestration, CCS, Widom-line

\title{
1. Introduction
}

Supercritical carbon dioxide is probably the most common supercritical fluid with a wealth of industrial applications. There are two reasons for that: $\mathrm{CO}_{2}$ is readily available, and it is a low-cost fluid. Also, it exists as a supercritical fluid over a wide pressure and temperature range, starting just a few degrees above room temperature and above 7.3 MPa. A novel application for which the thermophysical properties of supercritical $\mathrm{CO}_{2}$ need to be known is the "carbon capture and sequestration" (CCS). CCS has been identified as a realistic 
way to mitigate present global warming of the Earth. Figure 1 shows a sketch of the cycle of $\mathrm{CO}_{2}$ capture/production, transportation, then injection stages involved in CCS. Major technological and knowledge gaps, however, have to be filled in order to ensure CCS safety, the main challenge being to prevent $\mathrm{CO}_{2}$-leakage over a timelength of $\approx 10^{3}$ years. Thermophysical properties of supercritical $\mathrm{CO}_{2}$ mixtures, such as would be encountered in CCS cycle conditions, are identified as one field which particularly requires development of experimental and theoretical research (e.g., Bachu, 2000; Wilday and Bilio, 2014).

It is known that some properties (e.g., compressibility or density) of supercritical fluids behave anomalously in a narrow temperature-pressure band that starts at the critical point and extends to higher $T$ and $P$ values (Leneindre et al. 1973; Wang and Nur 1989; Thiéry 1996; Estrada-Alexanders and Trusler 1998; Xu et al. 2005; Oschwald et al. 2006; McMillan and Stanley 2010; Simeoni et al. 2010). These anomalies can be represented in a $P-T$ diagram by curves marking extrema or inflection points of the relevant thermodynamic properties; specific definitions are given in Section 2. These curves are collectively called Widom lines, although this term was originally used for the correlation length anomaly only (Xu et al. 2005). Different properties have different Widom lines, so this group of curves forms a Widom region, as has been shown for various real and model liquids (Brazhkin and Ryzhov 2011; Brazhkin et al. 2011; May and Mausbach 2012; Imre et al. 2012, Brazhkin et al. 2012; Brazhkin et al. 2014). In pressure-temperature space the Widom-lines are located in a wedge-shaped region (called Widom region), pointing to the critical point, marking the region where physico-chemical quantities (e.g., compressibility, heat capacities, density, thermal expansivity, speed of sound) show anomalous behaviour. Other names for this region are pseudocritical region, pseudoboiling region or pseudospinodal region. As was recently shown for water, the description of supercritical fluid flow involving this region requires special attention; some of the established methods for flow and thermal exchange calculations for normal liquids and gases cannot be used because they are not able to handle the abrupt changes related to these anomalies (Imre et al. 2012); for example with some well-established numerical codes used to describe fluid flow in nuclear power plants (like RELAP or WAHA), compressibility, heat capacity or density can be estimated only with a large uncertainty only (around $10 \%$ for the first two quantities and around 1\% for density) in the vicinity of the Widom-line (Imre and Tiselj 2012). Therefore knowledge of the location of this anomalous region is crucial whenever flow (including leaking) and heat exchange involving supercritical states are concerned, so that process designers can be warned against $P-T$ conditions that should be avoided or - if this is not possible - at which advanced calculation methods are 
necessary. Anticipating similar problems for carbon dioxide in the case of CCS, an accurate mapping of the $\mathrm{CO}_{2}$ Widom region is required in order to ensure that the supercritical $\mathrm{CO}_{2}$ will remain controllable under the $P-T$ conditions of deep geological storage (for the $P-T$ range of existing storage places, see the case studies later).

In general, any rapid pressure and/or temperature change in the Widom region might induce an unexpectedly large response. For example, compressibility is the response function for a pressure change, expressed in terms of volume change. When a region of anomalously high compressibility is crossed, even a minute pressure and/or temperature change can lead to a hardly controllable volume change. Depending on the actual $P-T$ path of the leak, either pseudo-boiling or pseudo-condensation (significant density change for a small $T$ or $P$ change, without real phase transition) can prevail. This can have a great influence on the leakage rate, since fluid flow is very sensitive to parameters changing during these pseudo-transitions (like density, compressibility, viscosity, etc.). Crossing the compressibility Widom line during the transportation or injection may cause problems with the flow regulation, because the very rapid compressibility variation can lead to pressure oscillations. Other quantities such as the viscosity, the correlation length and the diffusivity exhibit anomalous behaviour in the Widom region, too. Furthermore, the solubility of $\mathrm{CO}_{2}$ is strongly density-dependent and changes significantly in the Widom region. This fact is particularly relevant in CCS, since $\mathrm{CO}_{2}$ injection into deep saline aquifers is one of the potential ways envisaged to mitigate climate changes. Despite the fact that fluid density fluctuations in the Widom region obviously control the fluid capacity to dissolve $\mathrm{CO} 2$, we do not discuss their Widom lines in this work. This is because these properties cannot be readily calculated directly from equations of state without some additional assumptions.

Figure 1 shows a sketch of the cycle of $\mathrm{CO}_{2}$ capture/production, transportation, then injection, including a potential leakage stage. From site A (production or capture site), the gas is transported to the injection site (B). This transport happens under fully controlled conditions, and pressure and temperature can be kept outside the Widom region (during transportation, $T$ is usually below the critical temperature $T_{c}$ ). The injection process is also controlled (from injection site B to geological storage site C) although the well-bottom temperature is fixed by geological constraints. One or more Widom lines might be crossed during injection, but the effect of these anomaly-crossings can be at least partially controlled (or - in case of a serious problem - the injection process can be stopped). The third step is the migration of carbon dioxide within the reservoir (from $C$ to $D$ ). This is a fully uncontrolled process, but as it takes place inside the storage formation, the potential $P-T$ paths cannot be 
very long, and therefore it is not likely that any anomaly lines are crossed. The most problematic step is the potential leakage process ( $D$ to $E$ ) from the reservoir to the surface (or to the sea-floor, in case of off-shore storage). Here the pressure-temperature route of the leakage is fully uncontrolled (although the initial and final conditions are fixed). Therefore, during leakage, crossing this anomalous region might cause some deleterious effect. Knowledge of Widom region-related property changes is necessary for evaluating the safety of anthropogenic $\mathrm{CO}_{2}$ sequestration. Concerning the fate of $\mathrm{CO}_{2}$ injected into deep saline aquifers, models initially predicted that, at such sites, the injected $\mathrm{CO}_{2}$ plume would entirely be dissolved by the brine after $4000-5000$ years (e.g., Torp and Gale 1996, Al-Fattah et al. 2011). At the Sleipner pilot site (North Sea) however, $\mathrm{CO}_{2}$ has been continuously injected since 1996 into shallow, brine-saturated sandstone capped with a shale layer. In 2010 a mapping of the $\mathrm{CO}_{2}$ plume revealed, that the speed of the dissolution process had been overestimated (Ringrose et al. 2011). Thus, the potential problems related to Widom anomalies are worthwhile evaluating.

In this short note we are going to map the anomalous region for pure $\mathrm{CO}_{2}$ with respect to some thermodynamic properties relevant for flow and heat transfer, namely the density, the isothermal compressibility, the isobaric and the isochoric heat capacities, the isobaric thermal expansivity, and the speed of sound. Furthermore, the effects of some "contaminants" (like water or lower alkanes) will be considered. Finally, the potential problems related to the anomalies in the Widom region will be evaluated for six storage locations: Snøhvit and Sleipner in Norway, Nagaoka in Japan, Ketzin in Germany, and two natural $\mathrm{CO}_{2}$-storage analogues, Montmiral in France and Mihályi-Répcelak in Hungary.

\section{Supercritical anomalies - theoretical description}

Figure 2 shows the fluid phase diagram of carbon dioxide in $P-T$ projection, calculated with the Wagner-Span carbon dioxide reference equation of state (Span and Wagner 1996), using the ThermoC program (Deiters 2006). This equation of state (EoS) is highly accurate even for supercritical states; however, it cannot be used for mixtures. The vapour pressure curve runs from the triple point at about $216 \mathrm{~K}$ to the critical point at $304.2 \mathrm{~K}$ and 7.38 MPa (Suehiro et al. 1996). The border of the supercritical region, conventionally defined by the two conditions $P>P_{c}$ and $T>T_{c}$, is represented in Figure 2 by the two thick grey lines. An alternative definition of the supercritical region is also depicted in Figure 2. Here the Widom region is represented by a narrow grey band, with vapour-like and liquid-like regions lying below and above that region, respectively. The latter regions are more or less 
indistinguishable from the normal pressurized liquid or vapour in the sense that there is no drastic change of their relevant thermodynamic properties (see for example Pártay el al. 2006; Imre et al. 2012).

In the figure also the so-called liquid-vapour stability limit (spinodal) is shown, which represents the thermodynamic limit of overheating. By carefull heating a liquid one can cross the vapour pressure curve without inducing a phase transition (boiling) (Debenedetti 1996). In that case, , and as long as the spinodal is not approached, the $\mathrm{CO}_{2}$ will remain liquid; but this state is metastable, and intense - even explosive - boiling can happen at any moment. In a similar way, there is a limit of undercooling of the vapour phase, namely the vapour-liquid spinodal. The pressure of metastable liquids can be negative; in this case the metastability is induced by isotropic stretching rather than heating (Skripov 1974; Trevena 1986; Debenedetti 1996; Imre et al. 2002). In this work, the stability lines have been derived from the WagnerSpan EoS (Span and Wagner 1996). This equation of state was developed, and its parameters optimized, for the stable region of the phase diagram. Therefore the extension of metastable region might not be reliable, as it was already stated in the original Span and Wagner paper (1996) and discussed later in a similar case by Imre et al. (2013). This statement is valid for other reference equation of state, too - although this is often overlooked (Imre et al. 2013). Therefore the real locations of the spinodals might differ from the ones shown in Figure 2.

Metastable states located between the vapour pressure curve and the spinodals (Kraska et al. 2009) are responsible for some hysteresis which can also cause problems during $\mathrm{CO}_{2}$ processing (Benintendi 2014). Although spinodals end at the critical point without extending into the supercritical region, they need to be mentioned here because the Widom lines can be regarded as their "shadows" cast beyond the critical point.

In this work the following Widom lines are considered for supercritical carbon dioxide:

- the compressibility Widom line: The isothermal compressibility $\kappa_{T}$ is infinite along the spinodal curves and at the critical point. The associated Widom line is the locus of $\kappa_{T}$ maxima on the $P-T$ plane. Figure 3 a shows such a $\kappa_{T}$ maximum at the slightly supercritical pressure of 7.5 MPa. Figure $3 \mathrm{~d}$ shows the location of the maxima on the three-dimensional $P-T-\kappa_{T}$ space. They evidently become sharper and higher as the critical point is approached.

- the Widom lines of the isochoric or isobaric heat capacities $C_{P}$ and $C_{V}$, and of the thermal expansivity $\alpha_{P}$ : These properties become infinite at the critical point, and 
the associated Widom lines are therefore loci of maxima of these functions. Strong heat capacity means that a large amount of heat can be absorbed.

- $\quad$ the Widom line of the speed of sound: The speed of sound $c_{s}$ becomes zero at the critical point or along the spinodals; the associated Widom line is a locus of (nonzero) minima in the supercritical region (Figure 3b). This quantity has been included here as acoustic measurements are very important to map reservoirs.

- the density Widom line: The density $\rho$ has a discontinuity for subcritical temperatures. The associated Widom line is a locus of inflection points of the density function (Figure 3c). The density affects viscosity, diffusivity and solubility of $\mathrm{CO}_{2}$ and its potential mixtures.

Figure 3 shows that, at constant pressure, the properties $\kappa_{T}, c_{s}$ and $\rho$ undergo drastic changes in a relatively narrow temperature range. Similarly, on isothermal plots, these properties show drastic changes in a narrow pressure range. These changes are not phase transitions, but bear some similarity to them. For example while in phase transition, the fluid exhibits and abrupt density change at a fixed temperature (like in boiling from liquid density to vapour density); in the supercritical region a similar density change might happen, although not abruptly at a temperature, but in a temperature range.

In Figure 4, the Widom-lines for the quantities $\kappa_{T}, C_{P}$ and $C_{V}, \alpha_{P}, c_{s}$, and $\rho$ are plotted on the $P-T$ plane from the critical point to about $550 \mathrm{~K}$ and $50 \mathrm{MPa}$ using the Wagner-Span equation of state (Span and Wagner 1996). The line corresponding to the isothermal compressibility is the two-dimensional $P-T$ projection of the bold line in Figure $3 \mathrm{~d}$. The Widom line is plotted up to $7 P_{c}$ for carbon dioxide (where $P_{c}$ is the critical pressure). Beyond these pressures the extrema fall below the uncertainty of the equation of state and the effect of the Widom anomalies diminishes.

The Widom lines can be approximated by cubic polynomials:

$$
T=A+B P+C P^{2}+D P^{3}
$$

The coefficients of the polynomials are given in Table 1 . The polynomials include the critical point with an error of $10 \mathrm{mK}$.

It can be seen in Figure 4, that the anomalous zone (in pressure-temperature space) is bounded by the Widom line of the isothermal compressibility $\left(\kappa_{T}\right)$ from the high temperature side, while on the low temperature side it is bounded mostly by the Widom line of the density. Processes involving pressure-temperature routes crossing or approaching this region can be influenced by the Widom line related anomalies. 
The demonstration of a potential problem related to the crossing of density Widomline can be seen in Figure 5. An isothermal pressure drop (Figure 5a) at $T=306 \mathrm{~K}$ from 7.75 MPa to 7.65 MPa generates a density drop from 0.537 to $0.398 \mathrm{~g} / \mathrm{cm}^{3}$, which means that a $0.1 \mathrm{MPa}$ pressure drop (corresponding to a $10 \mathrm{~m}$ depth change in a hydrostatic pressure scale and an even smaller one on a lithostatic scale) can cause a density drop - or a volume expansion - of more than $25 \%$. This massive volume increase is sometimes called pseudoboiling because of its similarity to the boiling of a liquid (Oschwald et al. 2006). In similar manner, an isobaric temperature drop at $P=7.6 \mathrm{MPa}$ from 305.5 to $303.2 \mathrm{~K}$ (Figure $5 \mathrm{~b}$ ) generates a density increase from 0.524 to $0.436 \mathrm{~g} / \mathrm{cm}^{3}$, which means that a $0.2 \mathrm{~K}$ temperature drop (corresponding to a $10 \mathrm{~m}$ depth change at $20 \mathrm{~K} / \mathrm{km}$ thermal gradient or a $8 \mathrm{~m}$ depth change at $25 \mathrm{~K} / \mathrm{km}$ ) can induce a density increase of approximately $17 \%$. In analogy to the pseudo-boiling, this phenomenon should be called pseudo-condensation. During a leakage, density decrease caused by the pressure decrease and the density increase caused by the temperature decrease compete, therefore - depending on the actual $P$ - $T$ path of the leak either pseudo-boiling or pseudo-condensation can prevail.

\section{Supercritical anomalies: confronting theory with experiments}

In Figure 6, speed of sound values of supercritical $\mathrm{CO}_{2}$ calculated with the WagnerSpan EoS are compared with experimental results at 340.2 K (Wang and Nur 1989), 308.2, 313.2, and 318.2 K (Han et al. 2010), 300 and $350 \mathrm{~K}$ (Estrada-Alexanders and Trusler 1998). The agreement with respect to the locations and depths of the minima is very satisfactory. The presence of the minimum can be seen even by using the original van der Waals EoS, but obviously, in that case the quantitative agreement is not so good.

Incidentally, it is remarkable that the existence of supercritical anomalies has been known from experiments for several decades, while theoretical studies of the Widom region began merely a decade ago (Xu et al. 2005).

\section{Impure carbon dioxide}

The effect of a second component on the location and intensity of supercritical Widom anomalies is worth considering, because the stored carbon dioxide hardly remains pure. Complex $\mathrm{CO}_{2}$-hydrocarbon fluid mixtures are known to be generated during $\mathrm{CO}_{2}$ injection for enhanced oil recovery, and they are also found in some natural deep $\mathrm{CO}_{2}$ reservoirs (e.g., Orr and Jensens 1984; NASCENT Report 2005, Novak et al. 2013, Han et al. 2014, Novak et al. 2014). Thus, even if $\mathrm{CO}_{2}$ is injected as pure, it will mix with other compounds during 
storage, like nitrogen, oxygen, argon, hydrogen sulphide and water vapour, beside various gases like lower alkanes such as methane to hexane or heptane. Some organic contaminants like benzene, toluene, xylene, etc. - can even be dissolved from reservoir rocks and caprocks (Zhong et al. 2014).

As a "rule of thumb" concerning the displacement of the Widom-region due to the addition of a small amount of a second component, one might expect that a contaminant with higher critical temperature would shift the Widom-peak to higher temperatures, while one with lower critical temperature would do the opposite. But here caution is advised: the point at which the compressibility diverges is not identical with the critical point of a mixture. A mixture may undergo a phase separation even if its compressibility is positive for all pressures. Therefore, it is possible that portions of Widom lines close to a mixture critical point lie in a two-phase region. Another difficulty is that some contaminants may even cause liquid-liquid phase separation. It is therefore advisable to compute the Widom lines of mixtures at some distance from their critical points only (Kraska and Imre 2005, Deiters and Kraska 2012).

Critical points of several potential contaminants are shown on Figure 7a (data taken from NIST Chemistry Webbook 2014). Figure 7b illustrates the shifts in the Widom compressibility peaks that are induced by the addition of various amounts of methane or water into $\mathrm{CO}_{2}$ at a fixed pressure of $10 \mathrm{MPa}$. Since the Wagner-Span reference equation of state cannot be used for mixtures, here the Xiang-Deiters equation was used as implemented into the ThermoC package (Deiters 2006, Xiang and Deiters 2008). The compressibility peaks of methane- $\mathrm{CO}_{2}$ with various methane contents are shifted to lower temperature compare to that of pure $\mathrm{CO}_{2}$, consistent with the fact that methane has lower critical temperature than $\mathrm{CO}_{2}$. Similarly, the compressibility peaks of water- $\mathrm{CO}_{2}$ mixtures are shifted toward higher temperature, consistent with the fact that the water critical temperature is higher than that of $\mathrm{CO}_{2}$.

There is no general rule to predict the displacement of the Widom region on adding a second (third, fourth, ...) component and it is clear from Figure 7 that it can be shifted in any direction. Therefore, in CCS case studies, even when the $P-T$ conditions of transport, storage or of a potential leakage path are far from the pure $\mathrm{CO}_{2}$ Widom region, an unavoidable contamination of the stored carbon dioxide might change the situation in some extent.

\section{Leakage hazards}


Leakage is a well-known hazard for CCS. Leakage rates must be kept below 0.01\%/year (Hepple and Benson, 2003, Miles et al. 2005) to ensure that $\mathrm{CO}_{2}$ is stored over a sufficiently long time-span. The danger is complex; from small-scale leakage causing problems to local vegetation to potentially possible high-energy catastrophic pneumatic eruptions (Pruess 2008). One has to consider that the number of cracks can increase drastically after the introduction of high pressure gas into the reservoir (Eshiet and Sheng, 2014). Here we would like to discuss some leakage problems related to the Widom lines.

In Figure 8, various hydrostatic $P-T$ lines can be seen, calculated with temperature gradients of 25 and $30 \mathrm{~K} / \mathrm{km}$, with average surface temperatures of $5{ }^{\circ} \mathrm{C}$ and $15^{\circ} \mathrm{C}$ at atmospheric pressure of $0.1 \mathrm{MPa}$ using averaged water density (Pruess 2008). One hypothetical off-shore case is also considered, located below a 300 meter deep sea with a seafloor temperature of $2{ }^{\circ} \mathrm{C}$. For potential leakage routes, only the lower and upper $P-T$ conditions are fixed (or rather confined in a range) to be in agreement with the reservoir and surface or sea-bottom $P-T$ data. Given that lithostatic $P-T$ paths plot above hydrostatic ones, one can see that, in the case of pure $\mathrm{CO}_{2}$ storage, the possibility that Widom-lines should be crossed during leakage paths could only occur in places with a high surface temperature and having relatively high geothermal gradient. Obviously, the situation changes when the stored $\mathrm{CO}_{2}$ is contaminated, e.g. inside of the storage formation, by compounds having a low $T_{c}$ such as like methane. In this case the Widom-region would be shifted to lower temperatures, compatible with potential leakage routes.

While data for potential leakage routes are either non-existing or confidential, the $P-T$ conditions of some existing $\mathrm{CO}_{2}$ storage places can be compared with those of the pure $\mathrm{CO}_{2}$ Widom region (Figure 9). We are not going to give detailed case studies; the selected examples serve only to demonstrate that Widom lines are located within the $P-T$ range relevant in CSS. The studied locations are four existing storage places (Figures 9a-d: Snøhvit and Sleipner offshore Norway, Nagaoka in Japan, Ketzin in Germany) and two natural $\mathrm{CO}_{2}$ reservoirs as analogues for anthropogenic $\mathrm{CO}_{2}$ storage (Figures 9e-f: Montmiral in France and Mihályi-Répcelak in Hungary). The $P-T$ conditions are taken from various sources (see hereafter). In the figures, some $P-T$ paths of potential leaks in the selected sites are indicated by arrows; whenever these paths are crossing a Widom line, one should be prepared to handle it. For example in case of leakage in a network of narrow cracks, the temperature decrease will densify the uprising carbon dioxide, while the pressure drop will decrease its density. Depending on the actual geological conditions such as the pressure regime and temperature gradients, the volume of escaped gas might increase and therefore it might widen the 
originally narrow cracks. In other leakage routes, the volume might decrease and in the latter case, the leakage should remain of low intensity.

Figures 9a shows the $P-T$ storage conditions in the Utsira formation at Sleipner (North Sea), ranging from 25-42 ${ }^{\circ} \mathrm{C}$ and 8-11 MPa (Baklid et al. 1996; Bickle et al. 2007; Arts et al. 2010; Ringrose and Eiken 2011). It can be seen that various leakage routes might cross the relevant Widom lines (lines $\mathrm{b}$ and c), although with low probability, because leakage probably would start from the upper part of the formation, along a $P-T$ path like line "a", thus avoiding the anomalous region. The reported $P-T$ conditions are close to the Widom region, therefore even a slight inaccuracy - or a small amount of contaminants - can change to situation. Indeed, the seafloor depth changed by as much as $21 \mathrm{~cm}$ between 2002 to 2005 at Sleipner, due to deep sediment compaction (Alnes et al. 2008). Also, currents can sweep away thick piles of sediments at the seabottom. In conclusion, concerning the potential problems caused by Widom line crossing, Sleipner can be considered as a proper location for storing pure supercritical $\mathrm{CO}_{2}$. However, this conclusion may need to be refined because of the 2 mole- $\%$ $\mathrm{CH}_{4}$ contaminant (Arts et al. 2010), which might shift the compressibility maximum by approx. $5 \mathrm{~K}$ (see Figure 7b).

At the Snøhvit gas field (Barents Sea), the $\mathrm{CO}_{2}$ that is pumped up with hydrocarbon gas to the sea floor at $\sim 320 \mathrm{~m}$ water depth is re-injected into a sandy reservoir lying $\sim 2.6 \mathrm{~km}$ below sea level. The initial $P-T$ storage conditions were around $29 \mathrm{MPa}$ and $98-100{ }^{\circ} \mathrm{C}$ in 2008, but reservoir pressure has increased to $\sim 39 \mathrm{MPa}$ in 2011 after near-continuous $\mathrm{CO}_{2}$ injection, on account of limited permeability (Hansen et al. 2011, 2013). In Figure 9b it can be seen that the reported $P-T$ conditions are just in the middle of the anomalous region; therefore injection and leaking routes should cross them. In reality, contaminants (natural gas compounds) might push the Widom lines to lower temperatures, and the location of the storage state would probably be shifted between the Widom lines of thermal expansivity and compressibility, but into a region where anomalies are already weaker because the state is farther from the critical point. Snøhvit would not be a first pick for pure $\mathrm{CO}_{2}$ storage, but because of some other considerations - that the re-injected $\mathrm{CO}_{2}$ is locally produced, so that transportation is not a problem, and that it can even enhance oil recovery (EOR) - it might be a good choice.

The small-scale field of Nagaoka (Japan) was recently closed. Here well-head and well-bottom $P-T$ data are available $\left(7-11 \mathrm{MPa}, 32{ }^{\circ} \mathrm{C}\right.$; $19 \mathrm{MPa}, 48{ }^{\circ} \mathrm{C}$, respectively; Kikuta et al. 2005), but details about the $P-T$ storage conditions and their evolution are lacking. Figure 9c shows that injection conditions just before or in the well-head or in the well-head might 
cross several Widom lines because they are close to the problematic critical point region. Such instabilities can however be managed, as injection occurs under fully controlled conditions. Leaking paths theoretically might also intersect most Widom lines, but only along a very specific $P-T$ path. Therefore from this point of view, Nagaoka is a proper storage place.

The $P-T$ conditions of well Ktzi 200 from the Ketzin German pilot site are represented by a grey band in Figure 9d (Kempka and Kuhn, 2013, Loizzo et al. 2013). Injection is done along the vapour pressure line, through the critical point and then hardly above the Widom lines. A leak might lead to a crossing of Widom lines in this very anomalous region, or to a phase transition (boiling) on crossing the vapour pressure line, or even to explosive boiling of depressurized superheated $\mathrm{CO}_{2}$ (Kraska et al. 2009; Benintendi 2014). Concerning these points, the Ketzin pilot is far from optimal, although it might score better in other respects (Wiese et al. 2013), in particular a detailed geological knowledge of the storage site. It should be mentioned here, that according to some recent measurements, leakage - at least in the present stage - was not found in Ketzin (Wiese et al. 2013).

In case of Nagaoka and Ketzin, the storage conditions might reach subcritical states (pressure and temperature below the critical values); in that case a phase transition might occur. For such conditions, caution is required for flow-related calculations (see for example Schultz et al. 2013).

The study of natural deep $\mathrm{CO}_{2}$ reservoirs as analogues of long-term storage sites, concerning possible $\mathrm{CO}_{2}$ leakage, is also important to assess the safety of CCS over a time length of several thousand years. In Figure $9 \mathrm{e}$ and $9 \mathrm{f}$ the $P-T$ conditions of two such natural reservoirs (natural high-purity carbon dioxide accumulation) can be seen, Montmiral in France (Figure 9e) and Mihályi-Répcelak in Hungary (Figure 9f) (NASCENT Report 2005; Király et al. 2013). The $\mathrm{CO}_{2}$ at the former site has been exploited and it is still exploited in the latter. At Montmiral, $\mathrm{CO}_{2}$ is trapped in a $2400 \mathrm{~m}$ deep reservoir at $100{ }^{\circ} \mathrm{C}$ and $36 \mathrm{MPa}$. The $\mathrm{CO}_{2}$ is associated with oil, and the exploited $\mathrm{CO}_{2}$ gas contains $\sim 1.6$ mole- $\% \mathrm{CH}_{4}$ (Pauwels et al. 2007). One of the production wells at Mihályi-Répcelak is $1.2 \mathrm{~km}$ deep, with corresponding $\mathrm{CO}_{2}$ storage conditions of $73-75^{\circ} \mathrm{C}$ and $14.7-15.1 \mathrm{MPa}$. The $\mathrm{CO}_{2}$ is quite pure, with only a few mole-\% water. Because reservoir pressure is high in both places (2 to 4 times the $\mathrm{CO}_{2}$ critical pressure), the Widom lines would be crossed far above the critical point region in case of leakage, where the anomalies are less intense. For most of the specific $P-T$ leakage paths considered (like the middle arrow in Mihályi-Répcelak), the anomalies in the crosscut Widom region should not be sharp, but gradual, without any abrupt change. At 
Montmiral, the concentration in $\mathrm{CH}_{4}$ is too low to shift the Widom region to lower temperatures, thus potentially placing the reservoir in the middle of the Widom-region (Figure 9/e). Finally, because both reservoirs are geopressurized (pressure above hydrostatic), abrupt decompression paths can be envisaged. At Montmiral particularly, a change from geopressurized to hydrostatic regime would correspond to a drop in pressure of $\sim 10 \mathrm{MPa}$. Reservoir conditions would thus fall in the center of the Widom region and also closer to $\mathrm{CO}_{2}$ critical conditions. Such an evolution would thus favour potential leakage. The fact that the two natural accumulation places have existed for ages without any known problem indicates the nearly infinitesimal probability of problematic leaking routes for these reservoirs.

\section{Summary and Perspectives}

Predicting the flow of supercritical $\mathrm{CO}_{2}$ in reservoirs is a major challenge in connection with the safety of anthropogenic $\mathrm{CO}_{2}$ storage. For proper modelling of the sequestration steps $-\mathrm{CO}_{2}$ production/capture, transport, and injection into a reservoir - as well as for assessing the effects of potential leakage it is essential to have reliable and accurate thermodynamic data of $\mathrm{CO}_{2}$ in the relevant pressure and temperature ranges.

For supercritical carbon dioxide - just like for other supercritical fluids - there is a wedge-shaped region called Widom region, pointing to the critical point, where several physico-chemical quantities (e.g., compressibility, heat capacities, density, thermal expansivity, speed of sound) show anomalous behaviour. These properties become extremely sensitive to pressure or temperature variations and can therefore change drastically along supercritical $P-T$ paths. In geological environments the pressure and temperature depends on the actual depts. and the aforementioned properties are also depth-dependent. For example density might change even $25 \%$ by changing the depth with 10 meter. This theoretical evaluation is quite in line with the experimental conclusion following $\sim 15$ years of deep $\mathrm{CO}_{2}$ injection, that buoyancy forces are largely underestimated by current models (Ringrose, 2010).

In this paper several Widom lines of supercritical $\mathrm{CO}_{2}$ have been computed with the Wagner-Span reference EoS. The locations of these lines are compared with the $P-T$ range of four storage sites (Snøhvit and Sleipner offshore Norway, Nagaoka in Japan, Ketzin in Germany, and two natural $\mathrm{CO}_{2}$ storage analogues, Montmiral in France and Mihályi-Répcelak in Hungary), and the potential consequences of crossing any of the Widom-lines because of leaking $\mathrm{CO}_{2}$ were discussed. The effect of contamination with natural gas compounds on the location of the Widom region is also discussed. It is shown that, by properly choosing the $P-T$ 
conditions of injection and storage, most problems related to the anomalous behaviour of supercritical fluids can be avoided or at least minimized. Obviously, the best solutions would be to find reservoirs with caprocks having very low permeabilities (Edlmann et al. 2013) or to develop methods where only a small fraction of the fluid would be in the supercritical phase, like the storage of absorbed $\mathrm{CO}_{2}$ in coal mines (see for example Gonzalez-Nicieza et al. 2014).

\section{Acknowledgments}

A. R. I. gratefully acknowledges an "Albert's reunion grant" from the University of Cologne and an invitation as a guest professor at the University of Orléans for two months. This work could not have been completed without the support of these two Universities.

\section{References}

Al-Fattah, S.M., Barghouty, M.F., Dabbousi, B.O. (2011) Carbon Capture and Storage: Technologies, Policies, Economics, and Implementation Strategies, CRC Press 2011, Ch. 5. Alnes H, Eiken O, Stenvold T (2008) Monitoring gas production and CO2 injection at the Sleipner field using time-lapse gravimetry, Geophysics 73: 155-161.

Arts R, Chadwick A, Eiken O, Thibeau S, Nooner S (2008) Ten years' experience of monitoring $\mathrm{CO}_{2}$ injection in the Utsira Sand at Sleipner, offshore Norway, First Break 26:6572.

Bachu S. (2000) Sequestration of CO2 in geological media: criteria and approach for site selection in response to climate change. Energy Convers. Manage. 41, 953-970.

Baklid A, Korbøl R, Owren G (1996) Sleipner Vest $\mathrm{CO}_{2}$ disposal, $\mathrm{CO}_{2}$ injection into a shallow underground aquifer. Society of Petroleum Engineers (SPE), paper 36600.

Benintendi R (2014) Non-equilibrium phenomena in carbon dioxide expansion. Process Saf Environ Prot 92:47-59.

Bickle M, Chadwick A, Huppert HE, Hallworth M, Lyle S (2007) Modelling carbon dioxide accumulation at Sleipner: Implications for underground carbon storage. Earth Planet Sci Lett 255:164-176.

Brazhkin VV, Fomin YuD, Lyapin AG, Ryzhov VN, Tsiok, EN (2011) Widom line for the liquid-gas transition in Lennard-Jones system. J Phys Chem B 115:14112-14115.

Brazhkin VV, Ryzhov VN (2011) Van der Waals supercritical fluid: exact formulas for special lines. J Chem Phys 135:084503. 
Brazhkin VV, Fomin YuD, Lyapin AG, Ryzhov VN, Trachenko K (2012) Universal crossover of liquid dynamics in supercritical region. JETP Lett, 95:164-169.

Brazhkin VV, Fomin YuD, Ryzhov VN, Tareyeva EE, Tsiok EN (2014) The "true" Widom line for a square-well system. arXiv:1402.6540 [cond-mat.soft].

Debenedetti PG (1996) Metastable liquids: concepts and principles. Princeton University Press, Princeton.

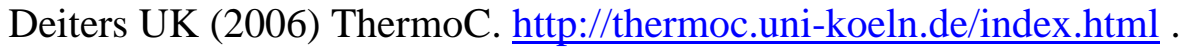

Edlmann K, Haszeldine S, McDermott C (2013) Experimental investigation into the sealing capability of naturally fractured shale caprocks to supercritical carbon dioxide flow. Environ Earth Sci 70:3393-3409.

Eshiet K, Sheng Y (2014) Investigation of geomechanical responses of reservoirs induced by carbon dioxide storage. Environ Earth Sci 71:3999-4020.

Estrada-Alexanders AF, Trusler JPM (1998) Speed of sound in carbon dioxide at temperatures between (220 and 450) $\mathrm{K}$ and pressures up to $14 \mathrm{MPa}$. J Chem Thermodyn 30:1589-1601.

Gonzalez-Nicieza C, Alvarez-Fernandez MI, Prendes-Gero MB, Pizarro-Garcia C, OlivaGonzalez AO (2014) An experiment-based assessment of the feasibility of the $\mathrm{CO}_{2}$ geological storage in unexploited coal beds in northern Spain. Environ Earth Sci 71:3673-3684.

Han DH, Sun M, Batzle M (2010) $\mathrm{CO}_{2}$ velocity measurement and models for temperatures up to $200{ }^{\circ} \mathrm{C}$ and pressures up to $100 \mathrm{MPa}$. Geophysics 75:E123-E129.

Han WH, Kim K-Y, Choung S, Jeong J, Jung N-H, Park E (2014) Non-parametric simulations-based conditional stochastic predictions of geologic heterogeneities and leakage potentials for hypothetical $\mathrm{CO}_{2}$ sequestration sites. Environ Earth Sci 71:2739-2752.

Hansen O, Eiken O, Østmo S, Johansen RI, Smith A (2011) Monitoring CO2 injection into a fluvial brine-filled sandstone formation at the Snøhvit field, Barents Sea. Society of Exploration Geophysicists - Expanded Abstract, No. SEG-2011-4092.

Hansen O, Gilding D, Nazarian B, Osdal B, Ringros P, Kristoffersen J-B, Eiken O, Hansen H (2013) Snøhvit: The history of injecting and storing $1 \mathrm{Mt} \mathrm{CO}_{2}$ in the fluvial Tubåen Fm.

Energy Procedia 37:356-3573.

Hepple RP, Benson SM (2003) Implications of surface seepage on the effectiveness of geological storage of carbon dioxide as a climate change mitigation strategy. In: Greenhouse Gas Technologies, 1, J Gale and Y Kaya (eds.), Elsevier, Amsterdam,pp 261-266.

Imre AR, Maris HJ, Williams PR (eds.) (2002) Liquids under negative pressure, NATO Science Series, Kluwer, Dordrecht. 
Imre AR, Deiters UK, Kraska T, Tiselj I (2012) The pseudocritical regions for supercritical water. Nucl Eng Des 252:179-183.

Imre AR, Tiselj I (2012) Reduction of fluid property errors of various thermohydraulic codes for supercritical water systems. Kerntechnik, 18-24.

Imre AR, Baranyai A, Deiters UK, Kiss PT, Kraska T, Quiñones-Cisneros SE (2013) Estimation of the thermodynamic limit of overheating for bulk water from interfacial properties. Int J Thermophys 34:2053-2064.

Kempka T, Kühn M (2013) Numerical simulations of $\mathrm{CO}_{2}$ arrival times and reservoir pressure coincide with observations from the Ketzin pilot site, Germany. Environ Earth Sci 70:36753685 .

Kikuta K, Hongo S, Tanase D, Ohsumi T (2005) Field test of $\mathrm{CO}_{2}$ injection in Nagaoka, Japan. In: Proceedings of the 7th Intl. Conf. on Greenhouse Gas Control Technologies, pp. $1367-1372$.

Király Cs, Szamosfalvi Á, Falus Gy, Szabó Cs, Sendula, E (2013) Expected physical and chemical effects of injecting industrial carbon dioxide on pore fluids and reservoir rocks based on the study of Mihályi-Répcelak natural $\mathrm{CO}_{2}$ occurrence. Magy Geofiz (in Hungarian with English abstract) 54:43-52.

Kraska T, Römer F, Imre AR (2009) The relation of interface properties and bulk phase stability: MD simulations of carbon dioxide. J Phys Chem B 113:4688-4697.

Leneindre B, Tufeu R, Bury B, Sengers JV (1973) Thermal conductivity of carbon dioxide and steam in the supercritical region. Ber Bunsenges Phys Chem 77:262-275.

Loizzo M, Henninges J, Zimmer M, Liebscher A (2013) Multi-phase equilibrium in a $\mathrm{CO}_{2}$ filled observation well at the Ketzin pilot site. Energy Procedia 37:3621-3629.

May H-O, Mausbach P (2012) Riemannian geometry study of vapor-liquid phase equilibria and supercritical behavior of the Lennard-Jones fluid. Phys Rev E 85: 031201.

McMillan PF, Stanley HE (2010) Going supercritical. Nat Phys, 6:479-480.

Miles N, Davis K, Wyngaard J (2005) Detecting leakage from $\mathrm{CO}_{2}$ reservoirs using micrometeorological methods. In: Carbon Dioxide Capture for Storage in Deep Geologic Formations - Results from the $\mathrm{CO}_{2}$ Capture Program. 2: Geologic Storage of Carbon Dioxide with Monitoring and Verification. Elsevier Science, London, UK, pp. 1031-1044

NASCENT Report - Natural Analogues for the Geological Storage of $\mathrm{CO}_{2}$. No. 2005/6. (British Geological Survey).

NIST Chemistry Webbook (2011) http://webbook.nist.gov/chemistry/ .

Novak K, Malvić T, Simon K (2014) Increased hydrocarbon recovery and $\mathrm{CO}_{2}$ management, a Croatian example. Environ Earth Sci 68:1187-1197. 
Novak K, Malvić T, Velić J, Simon K (2014) Increased hydrocarbon recovery and $\mathrm{CO}_{2}$ storage in Neogene sandstones, a Croatian example: part II. Environ Earth Sci 71:3641-3653.

Oschwald M, Smith JJ, Branam R, Hussong J, Schik A, Chehroudi B, Talley D (2006) Injection of fluids into supercritical environments. Combust Sci Technol 178:49-100.

Pártay LB, Jedlovszky P, Brovchenko I, Oleinikova A (2007) Percolation transition in supercritical water: a Monte Carlo simulation study. J Phys Chem B 26:7603-7609.

Pruess $\mathrm{K}$ (2008) On $\mathrm{CO}_{2}$ fluid flow and heat transfer behavior in the subsurface, following leakage from a geologic storage reservoir. Environ Geol 54:1677-1686, DOI 10.1007/s00254-007-0945-x.

Ringrose P (2010) IEA-GHG Summer School, Svalbard, http://ieaghg.org/docs/General_Docs/Summer_School/Philip_Ringrose_Storage_3.pdf

Ringrose P, Eiken O (2011) Sleipner and Snøhvit projects. CSLF Interactive Workshop, Saudi Arabia, 01-02 March 2011, Carbon Sequestration Leadership Forum.

Schulz FT, Glawe C, Schmidt H, Kerstein AR (2013) Toward modeling of $\mathrm{CO}_{2}$ multi-phase flow patterns using a stochastic multi-scale approach. Environ Earth Sci 70:3739-3748.

Simeoni GG, Bryk T, Gorelli FA, Krisch M, Ruocco G, Santoro M, Scopigno T (2010) The Widom line as the crossover between liquid-like and gas-like behaviour in supercritical fluids. Nat Phys 6:503-507.

Skripov, VP (1974) Metastable Liquids, Wiley, New York.

Span R, Wagner, W (1996) A new equation of state for carbon dioxide covering the fluid region from the triple-point temperature to $1000 \mathrm{~K}$ at pressures up to $800 \mathrm{MPa}$. J Phys Chem Ref Data 25:1509-1596.

Suehiro Y, Nakajima M, Yamada K, Uematsu M (1996) Critical parameters of $\left\{x \mathrm{CO}_{2}+(1-\right.$ $\left.x) \mathrm{CHF}_{3}\right\}$ for $x=(1.0000,0.7496,0.5013$, and 0.2522). J Chem Thermodyn 28:1153-1164.

Thiéry R (1996) A new object-oriented library for calculating analytically high-order multivariable derivatives and thermodynamic properties of fluids with equations of state. Comput Geosci 22:801-815.

Trevena DH (1987) Cavitation and tension in liquids. Adam Hilger, Bristol.

Wang Z, Nur A (1989) Effect of $\mathrm{CO}_{2}$ flooding on wave velocities in rocks with hydrocarbons. SPE Reservoir Eng 3:429-436.

Wiese B, Zimmer M, Nowak M, Pellizzari L, Pilz P (2013) Well-based hydraulic and geochemical monitoring of the above zone of the $\mathrm{CO}_{2}$ reservoir at Ketzin, Germany. Environ Earth Sci 70:3709-3726. 
Wilday J, Bilio M (2014) Safety issues for carbon capture and storage. Process Saf. Environ. Prot. 92, 1-2.

Xiang, H-W, Deiters,UK (2008) A new generalized corresponding-states equation of state for the extension of the Lee-Kesler equation to fluids consisting of polar and larger nonpolar molecules, Chem. Eng. Sci. 63:1490-1496.

Xu L, Kumar P, Buldyrev SV, Chen SH, Poole PH, Sciortino F, Stanley HE (2005) Relation between the Widom line and the dynamic crossover in systems with a liquid-liquid phase transition. Proc Natl Acad Sci USA 102:16558-16562.

Zhong L, Cantrell K, Mitroshkov A, Shewell J (2014) Mobilization and transport of organic compounds from reservoir rock and caprock in geological carbon sequestration sites. Environ Earth Sci 71:4261-4272. 
Figure legends

Figure 1. Schematic representation of carbon dioxide capture (production), transportation, injection, storage, migration and leakage (see text).

Figure 2. Phase diagram of fluid carbon dioxide (without solid phases) showing the limits of the conventionally defined supercritical region $\left(P>P_{c}\right.$ and $T>T_{c}$ domain, bracketed between the two thick grey lines) and the novel description showing the liquid-like, vapour-like and transitional (Widom) region. For subcritical region, various stable and metastable phases marked, separated by the (solid) vapour pressure line, the (dashed) liquid-vapour stability line (also called liquid-vapour spinodal) and by the (dot-dashed) vapour-liquid stability line (vapour-liquid spinodal).

Figure 3. (a) Isothermal compressibility $\kappa_{T}(\mathrm{~b})$, speed of sound $c_{s}$ and (c) density anomalies $\rho$ in the vicinity of the critical point, calculated by the Wagner-Span reference equation of state $(P=7.5 \mathrm{MPa}$; the dashed line indicates the critical temperature). (d) Three-dimensional pressure-temperature-compressibility plot, showing the corresponding Widom line (bold) running on the ridge, connecting the maxima.

Figure 4. Some relevant Widom lines of carbon dioxide. Points and error bars: calculated with the Wagner-Span reference equation of state, curves: polynomials (Eq. 1 with parameters from Table 1) representing the estimated locations of the extrema/inflection points of the marked quantities.

Figure 5. a: The phenomenon of "pseudo-boiling": an isothermal pressure drop ( $T=306 \mathrm{~K})$ of 1 bar generating a density drop of more than $25 \%$. b: The phenomenon of "pseudocondensation": an isobaric temperature $\operatorname{drop}(P=7.6 \mathrm{MPa})$ of $0.2 \mathrm{~K}$ causing a $17 \%$ density increase.

Figure 6.: Comparison of measured (symbols) and calculated (lines) speed of sound values $\mathrm{c}_{\mathrm{s}}$ as a demonstration of the applicability of the Wagner-Span equation of state to determine the location and extent of Widom anomalies. Sources of the data: 340.2 K (Wang and Nur 1989), 308.2, 313.2 and 318.2 $\mathrm{K}$ (Han et al. 2010), $300 \mathrm{~K}$ and $350 \mathrm{~K}$ (Estrada-Alexanders and Trusler, 1998).

Figure 7. (a) Critical points of various relevant contaminants (NIST Chemistry Webbook 2011). (b) The effect of one potential "contaminant" in supercritical $\mathrm{CO}_{2}$ on the location and 
size of the compressibility peak at $10 \mathrm{MPa}$, calculated with the Xiang-Deiters equation of state with Plöcker-Knapp-Prausnitz 1-fluid theory mixing rules (Xiang and Deiters, 2008). By adding methane to the carbon dioxide (mass ratios are marked in the figure), the peaks moved to lower temperatures, while by adding water, they moved to higher temperatures. Parameters: mole fractions of $\mathrm{CO}_{2}$ and the contaminant, - - - -: water, - - - --: methane.

Figure 8. Comparison of the location of Widom lines of $\mathrm{CO}_{2}$ with various hydrostatic $P-T$ routes. $\mathrm{x}$ : sea-floor conditions, grey circle: critical point.

Figure 9. Temperature and pressure relations of $\mathrm{CO}_{2}$ storage places and natural $\mathrm{CO}_{2}$ accumulations compared to the location of Widom lines. Potential leakage routes are marked by arrows. 
Table 1: Polynomial coefficients of Eq. 1 for the Widom lines studied in this work. $\mathrm{R}^{2}$ : correlation coefficient, range: pressure range of validity. The uncertainties of the coefficients are indicated by the last decimal digits.

\begin{tabular}{|l|l|l|l|l|l|l|}
\hline Quantity & $A / \mathrm{K}$ & $B / \mathrm{K} \cdot \mathrm{MPa}^{-1}$ & $C / \mathrm{K} \cdot \mathrm{MPa}^{-2}$ & $D / \mathrm{K} \cdot \mathrm{MPa}^{-3}$ & $R^{2}$ & Range/MPa \\
\hline$c_{s}$ & 244.5 & 8.37 & -0.062 & 0.00031 & 0.99992 & $7.5-50$ \\
\hline$C_{p m}$ & 265.3 & 6.18 & -0.097 & 0.00004 & 0.99251 & $7.5-50$ \\
\hline$C_{V m}$ & 233.2 & 12.73 & -0.464 & 0.00482 & 0.99704 & $7.5-20$ \\
\hline$\rho$ & 260.6 & 7.22 & -0.169 & 0.00111 & 0.99700 & $7.5-50$ \\
\hline$\alpha_{p}$ & 255.7 & 7.65 & -0.149 & 0.00113 & 0.99989 & $7.5-50$ \\
\hline$\kappa_{T}$ & 249.2 & 8.57 & -0.221 & 0.00796 & 0.99989 & $7.5-30$ \\
\hline
\end{tabular}


Figures

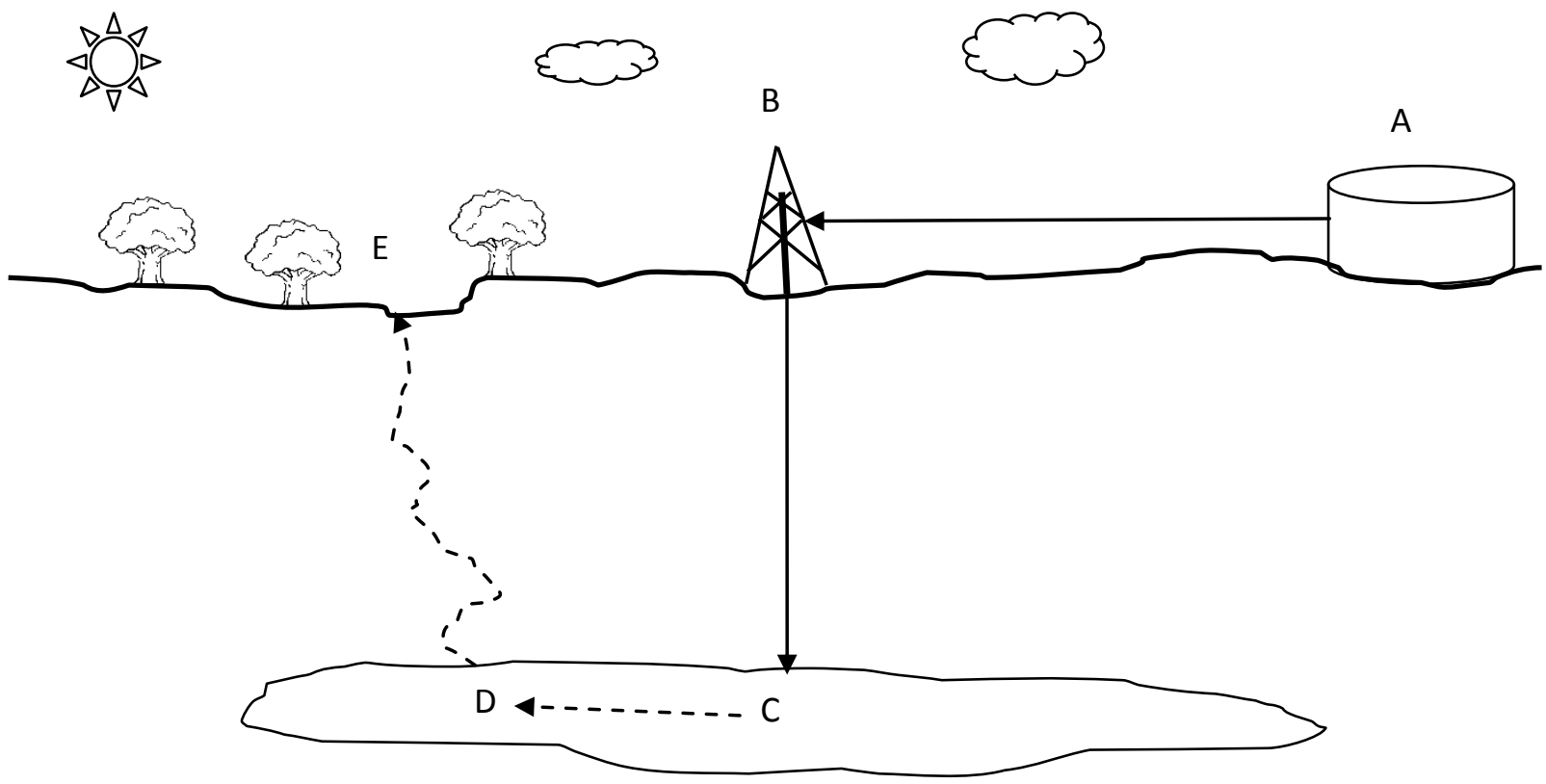

Figure 1.

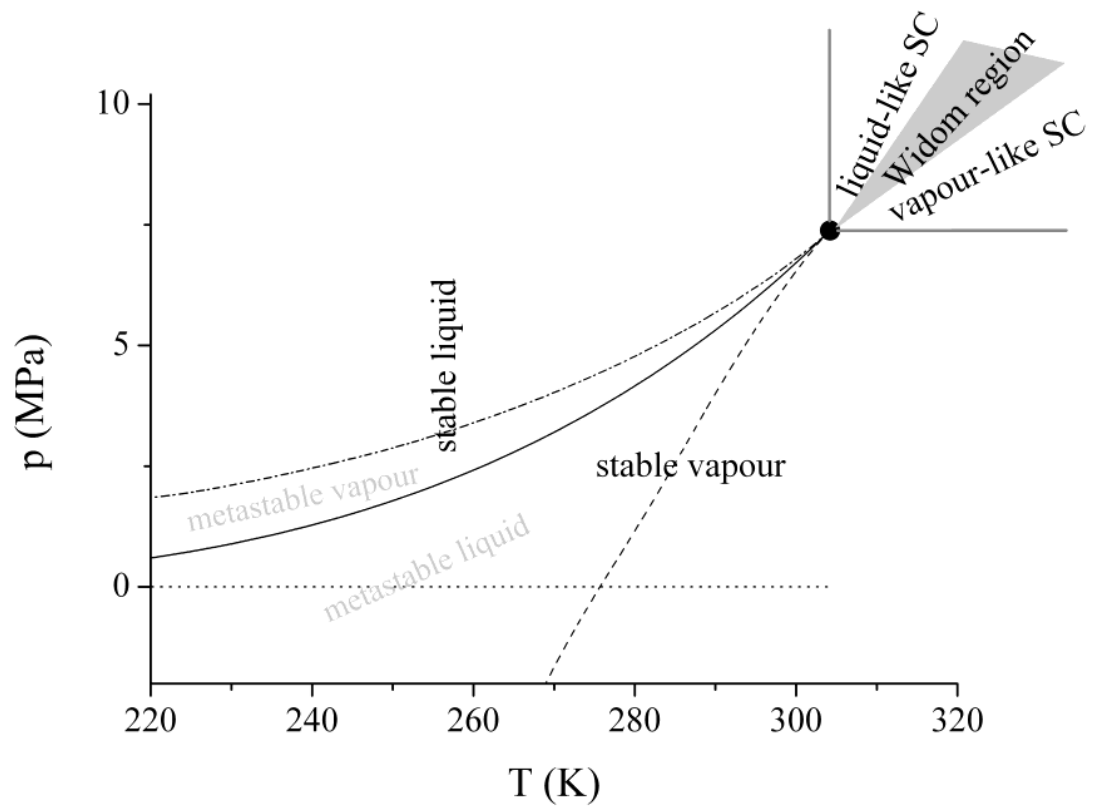

Figure 2 

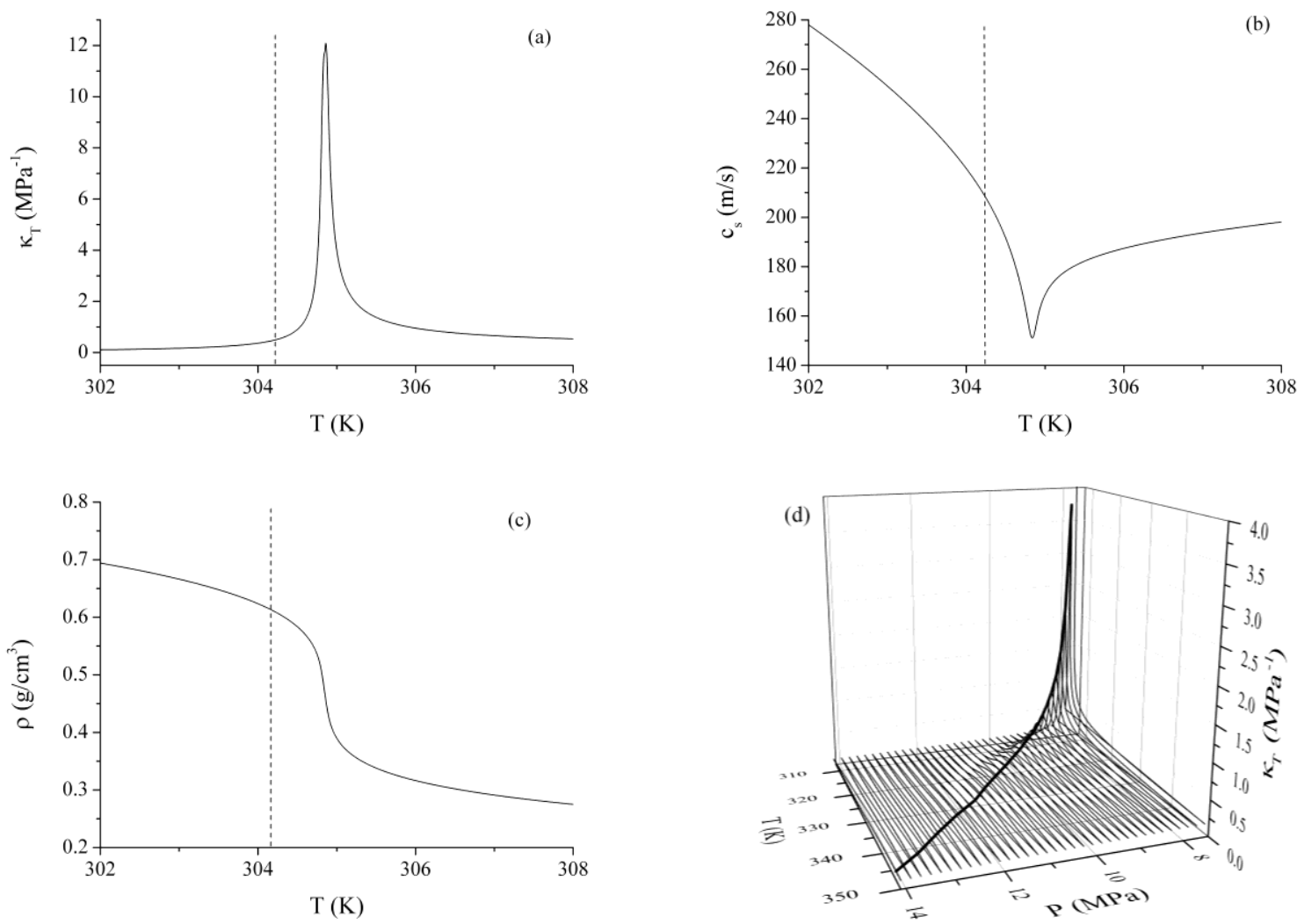

Figure 3.

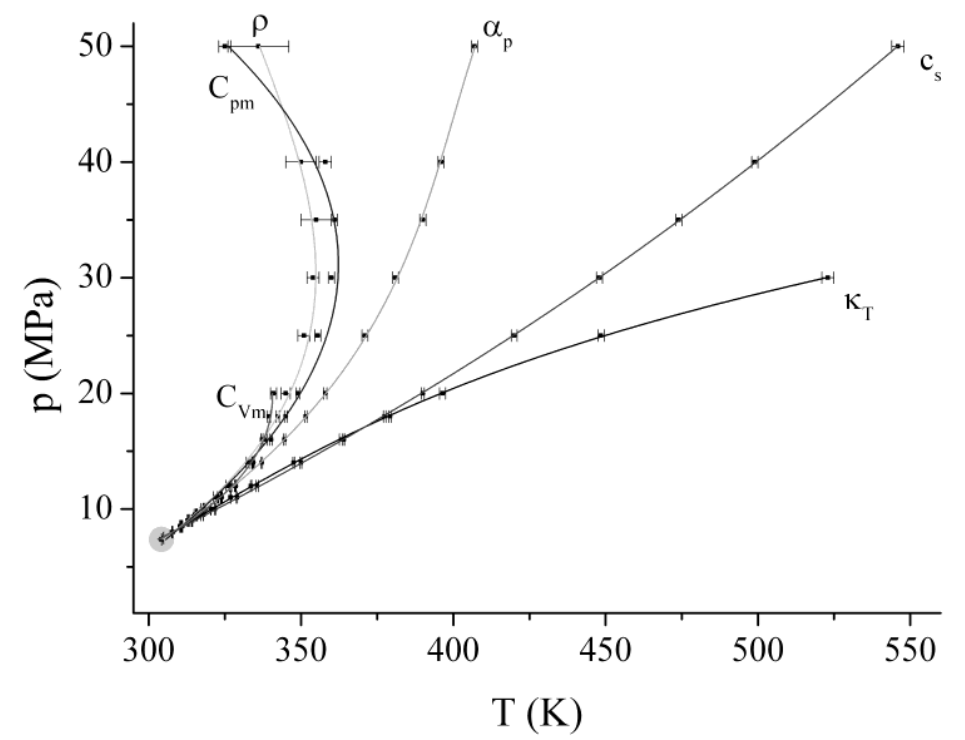

Figure 4. 

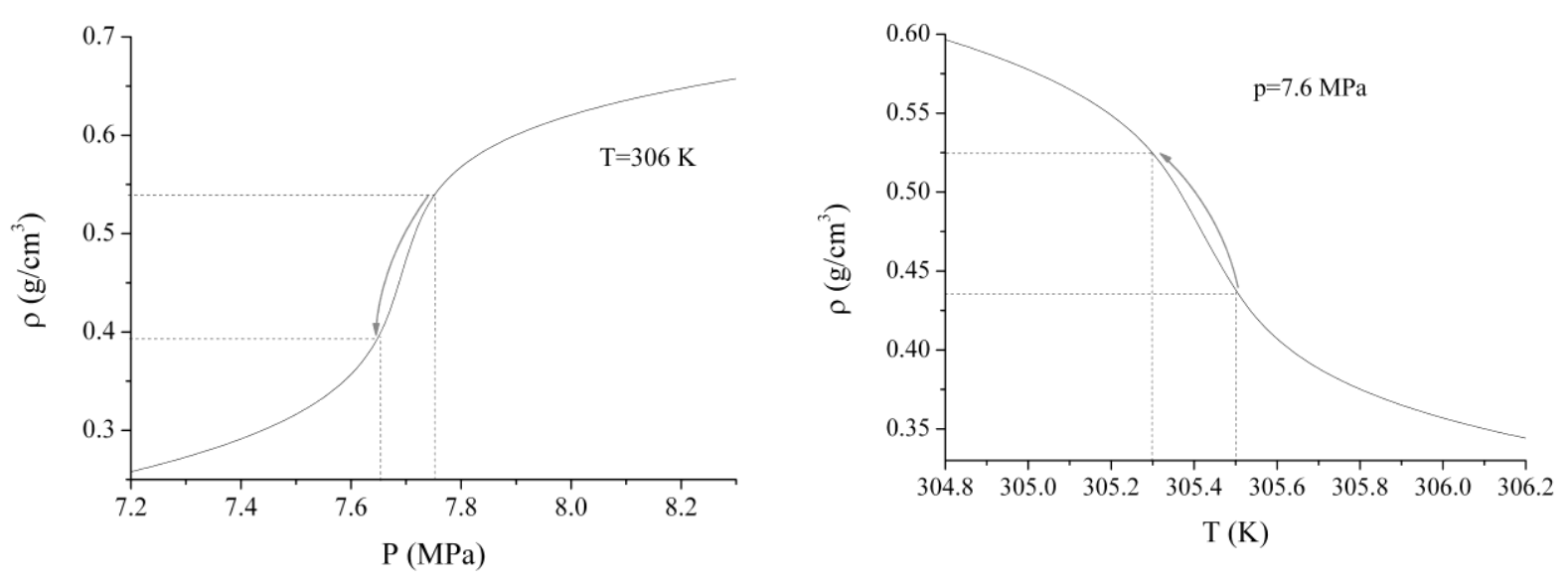

Figure 5.

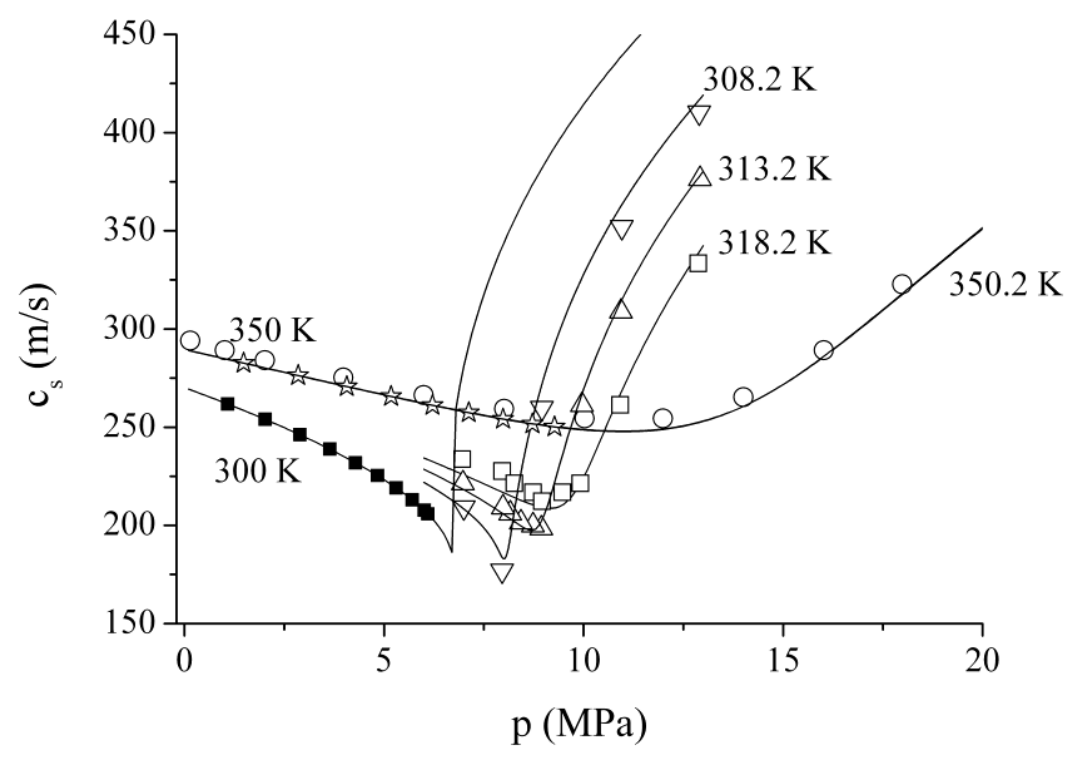

Figure 6. 

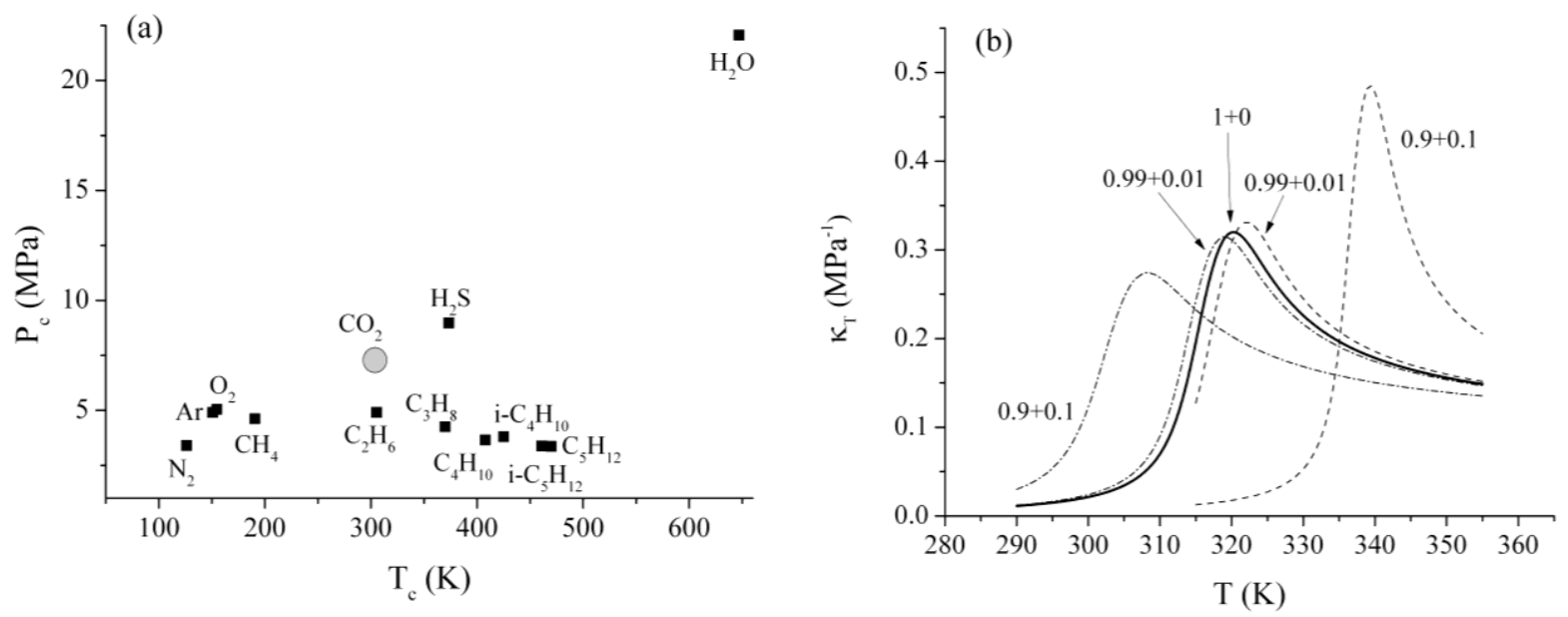

Figure 7.

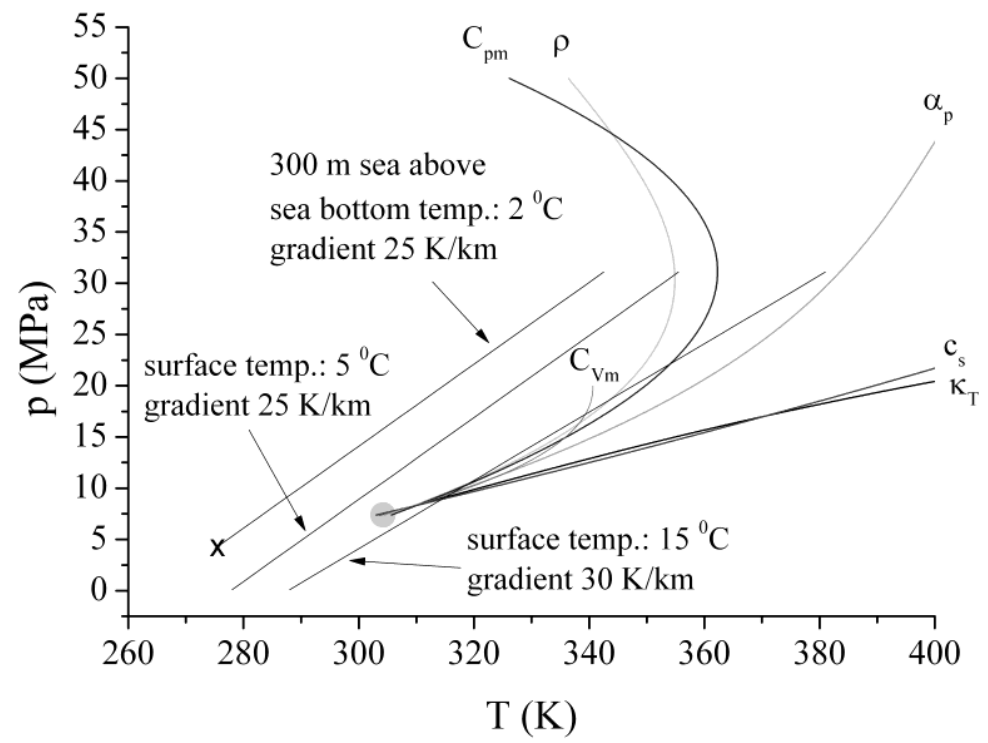

Figure 8. 

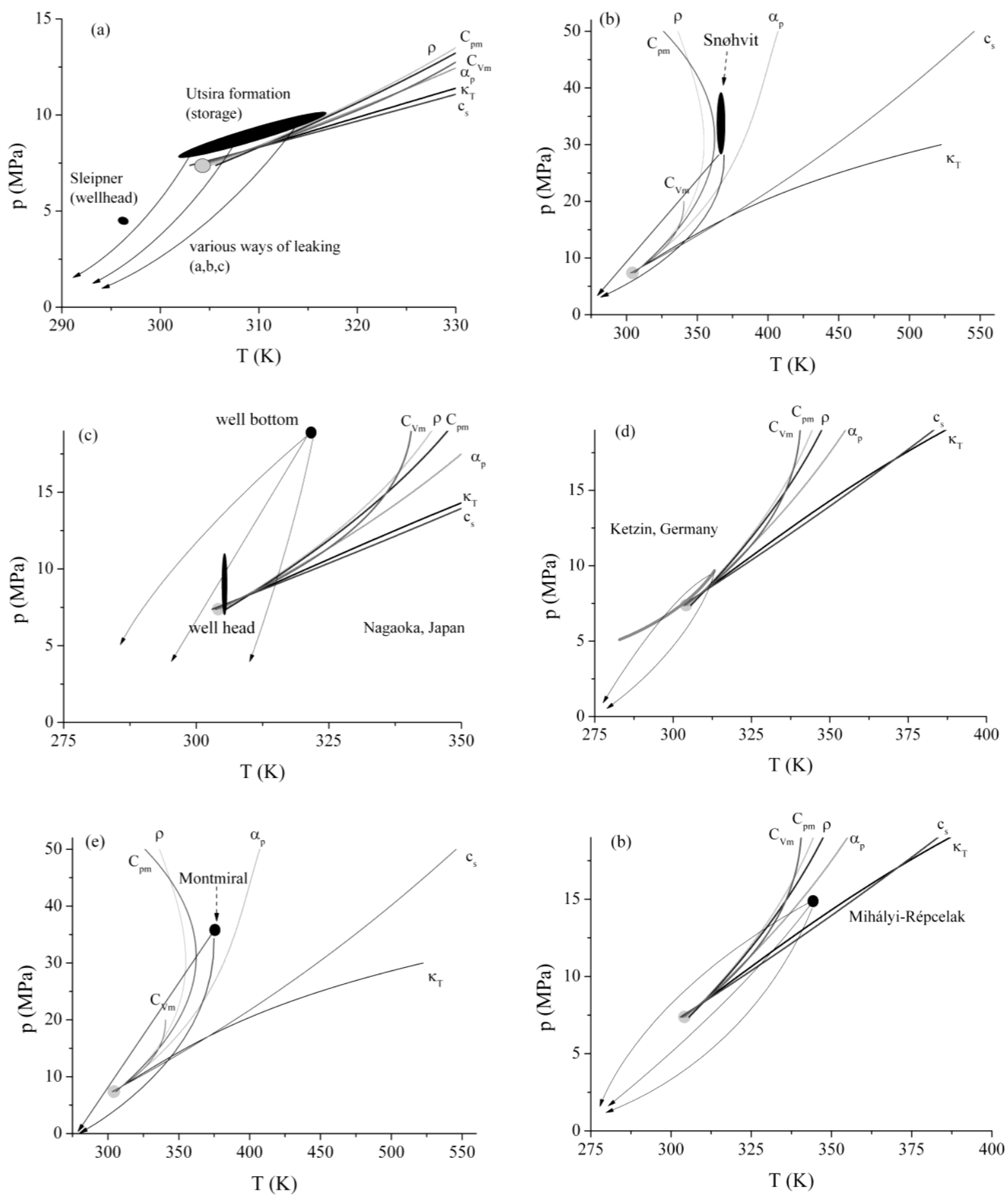

Figure 9. 